\title{
Exploring Frankl's Meaning, Purpose and Value of Life in Malaysian University Students
}

\author{
Ratna Roshida Ab Razak, Zatul Himmah Adnan, Ku Hasnita Ku Samsu, Zarina Muhammad, \\ Lee Yoke Fee
}

\begin{abstract}
This study has been using the Logotherapy approach, a therapy introduced by Viktor Frankl that emphasizes the meaning, purpose and value of life. Frankl's concept of purpose in life is based on a religious existential foundation which postulated that the essence of human motivation is the will to meaning. Frankl asserted that under any circumstance, there is a seed of meaning. (Frankl, 1997). The main purpose of this exploration study is to identify the meaning, purpose and value in life among university students in Malaysia. Based on Frankl's (1953) theory of purpose in life, Crumbaugh and Maholick (1964) developed the Purpose in Life Test (PIL) to measure the degree a person experiences a sense of meaning, purpose and value in life. This Purpose in Life Test (PIL) was psychometrically analyzed using a total number of 2586 university students to quantify the existential concept of meaning, purpose and value in life. Analysis of the data presented evidence that the Purpose in Life (PIL) test could be a larger dimension as well as being a scale in itself. The PIL showed a good internal consistency $($ Alpha $=0.930)$ and factor analysis revealed three factors which were categorized as Excitement of Life, Contentedness with life and Purpose and Goals in Life.
\end{abstract}

Index Terms: Logotherapy, Meaning, Purpose, Spirituality, Value

\section{INTRODUCTION}

According to Viktor E. Frankl's logotherapeutic the meaning of life lies in finding a purpose and taking responsibility for ourselves and other human beings. (Frankl, 1959) This theory was also called the Third Viennese School and was founded to help people to answer the existential questions such as, why we exist, what should we accomplish in life and what does life mean. It is a modality or method of dealing with life, exploring the range of one's freedom in responding to life responsibly in order to make life and living meaningful and significant. (Frankl, 1955).

The definition of meaning, purpose and value in life varies throughout the field since there is no universal meaning that can fit everyone's life. Purpose means a sense of fundamental goals, objectives, and direction in life that related to core

Revised Manuscript Received on September 22, 2019.

Ratna Roshida Ab Razak, Faculty of Human Ecology, Universiti Putra Malaysia, Serdang, Selangor, Malaysia

Zatul Hiummah Adnan, Faculty of Human Ecology, Universiti Putra Malaysia, Serdang, Selangor, Malaysia.

Ku Hasnita Ku Samsu, Faculty of Human Ecology, Universiti Putra Malaysia, Serdang, Selangor, Malaysia.

Zarina Muhammad, Faculty of Human Ecology, Universiti Putra Malaysia, Serdang, Selangor, Malaysia.

Lee Yoke Fee, Faculty of Human Ecology, Universiti Putra Malaysia, Serdang, Selangor, Malaysia. value and beliefs. By feeling unrestricted and certain of the purpose, founded with efficacy and self-worth, one would be able to value the world and to devote the live to pursue something virtuous for the common good. According to Danah Zohar, a management thought leader, physicist, philosopher and author for her best-selling books Spiritual Capital: Wealth We Can Live By and SQ - Spiritual Intelligence, by having deep meaning, essential purpose, and most significant values, one could be considered to be in the state of spiritual wellness. This spiritual wellness is a wealth, a capital, a power, and an influence that can be achieved by acting from a deep sense of meaning, our deepest values, and a sense of higher purpose, and all of these are best expressed through a life devoted to service. Based on this definition, spiritual wellness is the wellness by which one builds a spiritual capital. It is by seeking meaning in lives and acting in accordance with the deepest values that one can commit oneself to lives of responsibility based on the capacity that someone is best suitable for. She also passionately believed that a motivation to serve something larger than oneself, like family, community, humanity, the environment, future generations, and life itself - is the highest form our spirituality can take. According to Islam, it is such service, offered with grace and humility that puts us in touch with and become the servants of God in this world. With regard to that idea, Frank also proposed that a spiritual belief makes it easier for people to find meaning. However, it does not mean that one cannot find meaning without having faith.

Finding personal meaning is the main motivational principle of the human being, as the struggle for a sense of significance and purpose in life. Meaning in life can be defined as a personal experience that includes the understanding of order and consistency in purpose and value in one's existence, the pursuit and attainment of worthwhile goals, and an accompanying sense of self-realization, order, and coherence out of one's existence. This comprises of affective, motivational, cognitive, relational, and personal components which are closely related to the accomplishment of purpose, efficacy, value and justification, and self-esteem. (Steger, in press)

For today's students, dealing with questions of meaning, purpose and value has become more daunting than it was twenty years ago. Today's young people are getting wilder and run into a range of lifestyle, belief, and value-system choices far greater than the

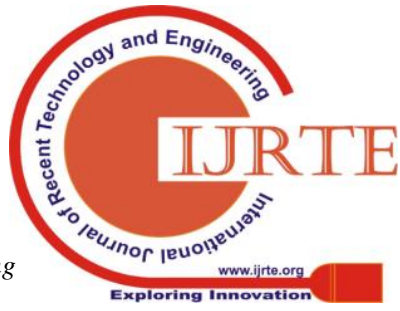


value-dominated community-based norms like the one in the '70 and '80s. No other social institution, apart from family institution, is as well positioned to help address these issues as school and university. By pursuing meaning, purpose and value they expressed for themselves, they came out ready to build their own meaningful lives.

Giving the importance of meaning, purpose and value in life, a primary goal of this study is to explore Frankl's meaning, purpose and value of life among Malaysian university students. The study has investigated the meaning, purpose and value of life, using a test based on Frankl's works (1997), known as Purpose in Life (PIL). This preliminary study was crucially important in order to provide a platform for determining the future exploration of Frankl's meaning, purpose and value among young generation, particularly the university students.

\section{FRANKL'S CONCEPT OF MEANING, PURPOSE AND VALUE IN LIFE}

\section{A. Purpose in Life Test}

Frankl (1997) postulated that the search for meaning is the primary motivational force in human existence. According to the current studies, having a sense of purpose or meaning in life is a strong and consistent predictor of psychological well-being (Chamberlain, 1987). Mariano (2007) pointed out that a sense of purpose is positively related to destructive behaviors in youth, whereas a sense of purposelessness is related to destructive behaviors in youth. In their review of studies on purpose, Zika and Chamberlain (1992) reported that "meaning in life is consistently related to positive mental health outcomes, while meaninglessness is associated with pathological outcomes" (p. 135). While there is rich research on the PIL and purpose in life, no recent research on the PIL specifically with university students was identified in the literature.

Based on Frankl's (1953) theory of purpose in life, Crumbaugh and Maholick (1964) developed the Purpose in Life Test (PIL) to measure the degree a person experiences a sense of meaning, purpose and value in life. The PIL test is a 20 -item self-report attitudinal scale, composed of 20 Likert-type response items on a 7-point scale designed to measure the level to which a respondent recognizes a general sense of meaning, purpose and in life. (Frankl, 1985). However for this study, a 5-point scale to make it easier for a respondent to make a decision.

PIL consists of 11 items which focus on the respondents' mood (e.g., item 1: I feel myself in need of life that, from in active and dull to energetic, 3 items which address life goals (e.g., item 3: I wish my life to be a person of, from just letting thing happen, to highly motivated), and 6 items which address meaning of life itself (e.g., item 4: In achieving something that I want, I am the type of person that have, from just wait and see to high determination). Even though, many studies regard the PIL test is a one dimensional model and report a single total score for the measure, Yalom (2008) and Melton \& Schulenberg (2008) point out that the items appear to relate to several different constructs, such as meaning of life, which includes purpose or goal, life satisfaction which comprises emotion like boredom, excitement and painfulness and how worthwhile one perceives one's life to be.

The PIL test has been used widely in research settings, clinical psychology and outpatient contexts, which has established a thread of relationships between the instrument and behavioral issues. The PIL test is the first and the most-studied questionnaire to measure perceived life purpose and meaning. Studies have proven PIL's effectiveness in determining levels of occupational meaningfulness. (Crumbaugh, 1968) In the present study, we used Crumbaugh and Maholick's PIL test to assess undergraduate student's responses to purpose in life. According to a study on PIL test, having a purpose in life clearly contributes to forming positive features such as strong values and healthy mental attitude. (Simmons, 1980) The idea proposed by Frankl in term of building life's meaning, purpose and value, can be regarded as a valuable asset in the field of humanistic psychology. Nevertheless, when there is profound research on meaning, purpose and value of life, there is still a huge gap in research on PIL and university students.

The PIL test has been widely used and appears to be reliable, though technical data can be difficult to locate. Cronbach's alpha estimates indicate that the PIL test is sufficiently reliable, though reliability estimates in divergent populations need to be established (Hutzell, 1988). For this study, the value of Cronbach's Alpha PIL is at 0.930 level, considered to be very satisfying. This value meets the general criteria that item variations should be associated with a common source. (DeVellis, 2003)

\section{B. Method}

For this study, students were asked to type in their age, gender/sex, and sexual orientation. They were also asked to select the best answer for race/ethnicity, residential setting, and socioeconomic status.

This test is designed to measure a person's sense of meaning, purpose and value. The test includes 20 statements. For each statement, the students rated themselves on a 5-point scale. The end points of each scale were descriptive anchors, and the middle position 4 was labeled as neutral. An example of a statement incorporated in the PIL included the question "I am usually..." and the choices of "completely bored" as one anchor of a five-point scale to "exuberant, enthusiastic" on the other. More positive and more negative anchors were rotated to different ends of the scale. In the example question given above, the more positive response of "exuberant, enthusiastic" is on the right side of the scale. The PIL also asks the question of "My life is" The more positive response anchor of "in my hands and I am in control of it" is on the left side of the scale, while the more negative anchor "out of my hands and controlled by external factors" was on the right. The final score was calculated by assigning the highest score of five points to the most positive anchor, and one-point to the most negative anchor. Adding the scores of each of the 20 statements created a composite PIL score of between 20 and 140 points. 
To conduct this study, a random sample of 2056 university students, enrolled full time at Malaysian public university, was selected. This group is the best group of people to represent the young generation of Malaysians whose age is between 19-25, as stated in the UNESCO charter, "The definition of youth can be based on the example of the definition given in the African Youth Charter where" youth "means" everyone aged between 15 and 35 years old " (UNESCO, 2006) Students were contacted by lecturers and they were required to complete the questionnaire. As an incentive, those who have participated in the study, were given a small token of appreciation.

Majority of the respondents consisted of those who were 19-23 years old with a total of 1848 people with $89.9 \%$. This was followed by respondents aged 24-28 who were 164 people with $8.1 \%$. Respondents who did not disclose their age were at least 42 people, equivalent to $2.0 \%$. "

Male respondents recorded 787 persons or $38.2 \%$, while female respondents were 1263 or $61.3 \%$ while those who did not answer were 8 persons or $0.4 \%$. This shows that female respondents have a higher percentage than male respondents.

A total of 1129 people (54.9\%), representing Malay ethnic, 487 people $(23.7 \%)$ consisting of ethnic Chinese, 230 (11.2\%), ethnic Indian, 126 (6.1\%), Bumiputra Sabah and 20 (1\%) comprising Bumiputra Sarawak . A total of $2(0.1 \%)$ did not state their ethnicity. In summary, the ethnic Malays were the majority in this study with a percentage of $54.9 \%$ of the total number of respondents.

The table above shows that the percentage of Muslim respondents is 1222 people (59.4\%). While Buddhism is 398 people (19.2\%), Hinduism is 199 (9.7\%), 215 Christians $(10.4 \%)$ and other religions are $13(0.6 \%)$. Serials of 11 $(0.5 \%)$ respondents did not respond to their religious beliefs.

A total of 10 public universities, representing 10 different regions were involved in this study. Respondents from UUM amounted to 199 persons $(9.7 \%)$ and 200 students $(9.7 \%)$ were from USM, 208 students (10.1\%) from UM. 200 students (9.7\%) from UKM, 199 students ( 9.7\%) from UTEM. For UTM, 200 students $(9.7 \%)$ have involved, 224 students $(10.9 \%)$ were from UMT, 218 students $(10.6 \%)$ were from UMK and 200 students $(9.7 \%)$ from UNIMAS and 208 students $(10.2 \%)$ were from UMS.

A total of $954(46.4 \%)$ respondents were students from the Faculty of Social Science and Humanities. A total of 1089 $(53.0 \%)$ were students from the Faculty of Science and Technology. A total of $13(0.6 \%)$ respondents did not specify their faculty.

For the year of respondents, 841 students (40.9\%) from year 1, 490 students $(23.8 \%)$, from year two, 638 students $(31 \%)$ from year three and 80 students $(3.9 \%)$ from year 4 . While 7 students $(0.4 \%)$ did not respond.

\section{RESULT AND ANALYSIS}

The purpose of this study is to determine the presence of meaning, purpose and value among the Malaysian university's students.

This 20-item version of the PIL test score was divided into
3 levels, which is (1.00-2.33) as low that suggest a lack of life meaning, purpose and value, (2.34-3.67) reflect moderate levels of meaning, purpose and value, and (3.68-5.00) as high meaning, purpose and value of life. (Crumbaugh and Maholick 1964).

\begin{tabular}{lll}
\hline Level & Frequency & Percentage \\
\hline Low (1.00-2.33) & 51 & $2.5 \%$ \\
Medium & 517 & $25.1 \%$ \\
$(\mathbf{2 . 3 4 - 3 . 6 7 )}$ & & \\
High (3.68-5.00) & 1488 & $72.4 \%$ \\
Total & 2056 & $100 \%$ \\
\hline
\end{tabular}

$\mathrm{Min}=3.96 \mathrm{SD}=0.661$

As shown in the Table 1: Level of PIL, for the PIL test's score, the mean was 3.96 with its Standard Deviation (SD) was 0.661 . This finding depicted that majority $(72.4 \%)$ with the frequency distribution was 1488 students, are typically interpreted as high degree of meaning, purpose and value in high life. Only $2.5 \%$ (51 students) shared the low level of meanings, purpose and value of life and 25.1\% (517 students) were at the medium level of meaning, purpose and value. The PIL showed a good internal consistency (Alpha= 0.930) and factor analysis revealed three factors which were categorized as Excitement of Life, Contentedness with life and Purpose and Goals in Life.

According to Crumbaugh \& Maholick (1969), those with higher PIL scores suffer less anxiety and have greater self-confidence. Those with higher scores of PIL also have better self-acceptance and social attitudes (Pearson \& Sheffield, 1975).We could understand that majority students were at high level of the state of spiritual wellness, which means they have a clear meaning, purpose and value of life. They have a huge potential to be strengthened and to be unleashed, particularly as a state machinery and critical enabler for driving and sustaining Malaysia's economic growth without compromising the well-being of the society.

\section{ADDITIONAL RESEARCH}

This study provided an initial investigation of meaning, purpose and value in life of Malaysian university students, using the PIL Test based on Frankl's conception of purpose in life. The results of this study indicated that Malaysian university students have a high level of sense of meaning, purpose and value in life, as measured by the PIL. However, additional study is needed to know if the environmental and involvement activities of college students had a relationship with a student's sense of purpose in life. Do the activities that involved students, develop a practical framework for helping students to develop a concrete plan for putting these suggestions into action. 


\section{CONCLUSION}

This kind of study is fundamental important and more empirical research is needed in order to help student affairs professionals to give greater attention to helping student find meaning, purpose and value in life. Having a sense of meaning, purpose and value in life is a solid and stable predictor of psychological well-being. (Reker, Peacocok and Wong, 1987). Frankl (1978) went as far as to postulate that seeking meaning is the core motivation and very crucial not only for well-being, but for survival. According to a research from Universiti Kebangsaan Malaysia's Department of Community Health, Department of Psychiatry and Department of Family Medicine published in the Asian Journal of Psychiatry in 2013, showed that both depression and anxiety scores were significantly higher among older students, with the age of 20 and above, and those born in rural areas. Stress scores were significantly higher among older students, females, Malays and those whose family had either low or high incomes compared to those with middle incomes. Thus, this type of research which revolves around the question of meaning, purpose and value is timely important because as reported Zika and Chamberlain (1992), that "meaning in life is consistently related to positive mental health outcomes, while meaninglessness is associated with pathological outcomes."

\section{REFERENCES}

1. UNESCO, Education for all: literacy for life; EFA global monitoring report, 2006.

2. Crumbaugh, J. C., \& Maholick, L. T. (1964). An experimental study in existentialism: The psychometric approach to Frankl's concept of noogenic neurosis. Journal of Clinical Psychology, 20, 200-207.

3. Crumbaugh, J. C., \& Maholick, L. T. (1969). Manual of instructions for the Purpose-in-Life-Test. Munster: Psychometric Affiliates.

4. De Vellis, R. F. (2003), Scale Development: Theory and Applications (2nd ed., Vol. 26). Thousand Oaks, CA: Sage Publications.

5. Davies G., Klaassen D., Längle A. (2014) Purpose in Life Test. In: Michalos A.C. (eds) Encyclopedia of Quality of Life and Well-Being Research. Springer, Dordrecht.

6. Frankl, V. (1959), Man's search for meaning, New York: Random House

7. Frankl, V. (1955), The doctor and the soul, New York: Random House.

8. Frankl, V. (1997), Viktor Frankl recollections: An autobiography, New York: Plenum

9. Frankl, V.E. (1978), The Unheard Cry for Meaning, Psychotherapy and Humanism. New York: Simon and Schuster.

10. Hutzell, R. R. (1988), A review of the Purpose in Life Test, International Forum for Logotherapy, 11(2), 89-101.

11. Steger, M. F. (in press). Experiencing meaning in life: Optimal functioning at the nexus of spirituality, psychopathology, and well-being. In P. T. P. Wong \& P. S. Fry (Eds.), The human quest for meaning. New York, NY: Routledge. Retrieved from http://www.michaelfsteger.com/?page_id=119.

12. Simmons, D. D. (1980). Purpose in life and the three aspects of valuing, Journal of Clinical Psychology, 36, 921-922.

13. Paul R. Pearson Brian F. Sheffield, (1975), Purpose in life and social attitudes in psychiatric patients, Journal of Clinical Psychology, pp. 330-332.

14. Reker, G.T. Peacock, E.J. \& Wong, P.T. (1987), Meaning and purpose in life and well-being: A life-span perspective, Journal of Gerontology, 42, pp. 44-49.

15. Mariano, J. M. (2007) The relationship of purpose to character strengths in emerging adulthood, Dissertation Abstracts International, (AAT $3245590)$

16. Melton, A. M. A., \& Schulenberg, S. E. (2008). On the measurement of meaning: Logotherapy's empirical contributions to humanistic psychology. The Humanistic Psychologist, 36(1), 31-44.

17. Meier, A., \& Edwards, H. (1974), Purpose-in-Life Test: Age and sex differences. Journal of Clinical Psychology, 30(3), 384-386.
18. Yarnell, T. D. (1971), Purpose-in-Life Test: Further correlates, Journal of Individual Psychology, 27(1), 76-79.

19. Yalom, I. D. (1980), Existential psychotherapy, New York, NY: Basic Books.

20. Zika, S., \& Chamberlain, K. (1992), On the relation between meaning in life and psychological well-being. British Journal of Psychology, 83(1), 133-145.

21. Hutzell RR, Peterson TJ., 1986, Purpose Questionnaire with an alcoholic population, International Journal of Addiction, Jan: 21 (1), Use of the Life

22. G. O. Young, "Synthetic structure of industrial plastics (Book style with paper title and editor)," in Plastics, 2nd ed. vol. 3, J. Peters, Ed. New York: McGraw-Hill, 1964, pp. 15-64.

23. W.-K. Chen, Linear Networks and Systems (Book style). Belmont, CA: Wadsworth, 1993, pp. 123-135.

24. H. Poor, An Introduction to Signal Detection and Estimation. New York: Springer-Verlag, 1985, ch. 4.

25. B. Smith, "An approach to graphs of linear forms (Unpublished work style)," unpublished.

26. E. H. Miller, "A note on reflector arrays (Periodical style-Accepted for publication)," IEEE Trans. Antennas Propagat., to be published.

27. J. Wang, "Fundamentals of erbium-doped fiber amplifiers arrays (Periodical style - Submitted for publication)," IEEE J. Quantum Electron., submitted for publication.

28. C. J. Kaufman, Rocky Mountain Research Lab., Boulder, CO, private communication, May 1995.

29. Y. Yorozu, M. Hirano, K. Oka, and Y. Tagawa, "Electron spectroscopy studies on magneto-optical media and plastic substrate interfaces(Translation Journals style)," IEEE Transl. J. Magn.Jpn., vol. 2 Aug. 1987, pp. 740-741 [Dig. (th $^{\text {th }}$ Annu. Conf. Magnetics Japan, 1982, p. $301]$.

30. M. Young, The Techincal Writers Handbook. Mill Valley, CA: University Science, 1989.

31. (Basic Book/Monograph Online Sources) J. K. Author. (year, month, day). Title (edition) [Type of medium]. Volume(issue). Available: http://www.(URL)

32. J. Jones. (1991, May 10). Networks (2nd ed.) [Online]. Available: http://www.atm.com

(Journal Online Sources style) K. Author. (year, month). Title. Journal [Type of medium]. Volume(issue), paging if given. Available: http://www.(URL)

33. R. J. Vidmar. (1992, August). On the use of atmospheric plasmas as electromagnetic reflectors. IEEE Trans. Plasma Sci. [Online]. 21(3). pp. $876-880$. http://www.halcyon.com/pub/journals/21ps03-vidmar

Available:

\section{AUTHOR PROFILE}

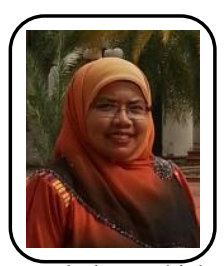

Ratna Roshida Ab Razak is an Associate Professor of the Department of Government and Civilizational Studies at the University Putra Malaysia. She earned her first degree B. Human Sciences (Hons) 1995 from International Islamic University Malaysia (IIUM), MA (1996) and PhD (2000) from Leeds University, UK. Her areas of interest in research and publication are civilizational studies. spirituality and humanistic psychology which she formalized in her $\mathrm{PhD}$ on this subject, and came out with a book entitled, Understand Al-Mutanabbi: A Humanistic Psychological Approach. Her main research area is about meaning, purpose and value in life. She has presented papers at conferences both home and abroad, published articles and papers in various journals, and contributed a chapter to the book Civilizational Competences and Regional Development in Poland (Warsaw University Press, 2009). She has published in such journals as, British Journal of Arts and Social Sciences, The International Journal of Humanities, KEMANUSIAAN: The Asian Journal of Humanities, The Islamic Quarterly, Akademika, Jurnal Peradaban and so on. She has taught a number of courses such as Islamic and Asian Civilization (TITAS), Ethnic Relation, Critical Thinking, Major Themes in Selected World Religions, Asian Thought: Indian, Japanese and Chinese and, Islamic Thought and Social Changes.

I am Ratna Roshida Ab Razak, affiliated with Faculty of Human Ecology, Universiti Putra Malaysia, Serdang, Selangor, Malaysia. I am very much interested Humanities.

My name is Zatul Hiummah Adnan, affiliated with Faculty of Human Ecology, Universiti Putra Malaysia, Serdang, Selangor, Malaysia. My area of interest is Human development.

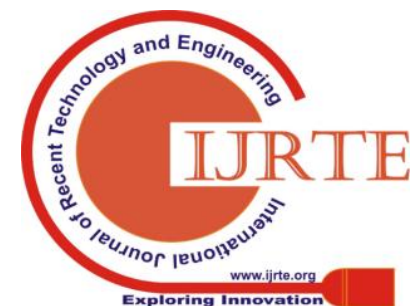


My name is Ku Hasnita Ku Samsu, I am affiliated with Faculty of Human Ecology, Universiti Putra Malaysia, Serdang, Selangor, Malaysia. My area of interest is Human Development.

I am Zarina Muhammad, Lucky to connect with Faculty of Human Ecology, Universiti Putra Malaysia, Serdang, Selangor, Malaysia. My area of interest is Human development.

My good name is Lee Yoke Fee, my affiliation is Faculty of Human Ecology, Universiti Putra Malaysia, Serdang, Selangor, Malaysia. I am interested in Humanity and development. 